\title{
Current concepts of the management of dental extractions for patients taking warfarin
}

\author{
G Carter,* AN Goss, $†$ J Lloyd, $\ddagger$ R Tocchetti
}

\begin{abstract}
Background: Controversy has surrounded the correct management of patients therapeutically anticoagulated with warfarin who require dental extractions. The risk of bleeding must be weighed up against the risk of thromboembolism when deciding whether to interfere with a patient's warfarin regimen. An improved understanding of the importance of fibrinolytic mechanisms in the oral cavity has resulted in the development of various local measures to enable these patients to be treated on an outpatient basis.

Methods: A review of the literature was undertaken. This was supplemented by the authors' clinical trials and extensive clinical experience with anticoagulated patients.

Results: Various protocols for treating patients taking warfarin have been reviewed and summarized and an overview of the haemostatic and fibrinolytic systems is presented. A protocol for management of warfarinized patients requiring dental extractions in the outpatient setting is proposed.

Conclusions: Patients therapeutically anticoagulated with warfarin can be treated on an ambulatory basis, without interruption of their warfarin regimen provided appropriate local measures are used.
\end{abstract}

Key words: Warfarin, anticoagulation, extractions, oral surgery.

(Accepted for publication 23 December 2002.)

\section{INTRODUCTION}

Warfarin is the most commonly prescribed oral anticoagulant used to prevent and treat thromboembolism. Because this is a long-term

\footnotetext{
"Senior Registrar, Oral and Maxillofacial Surgery Unit, Royal Adelaide Hospital, Adelaide Dental Hospital and The University of Adelaide, South Australia.

tProfessor and Director, Oral and Maxillofacial Surgery Unit, Royal Adelaide Hospital, Adelaide Dental Hospital and Professor of Oral and Maxillofacial Surgery, School of Dentistry, The University of Adelaide.

$\ddagger$ Director, Haemostasis and Thrombosis Unit, Division of Haematology, Royal Adelaide Hospital.

\$Senior Medical Scientist, Biotherapeutic Services, Division of Haematology, Royal Adelaide Hospital.
}

treatment, the number of such patients requiring dental extractions is on the rise. Patients receiving warfarin who undergo dental extractions may have prolonged and excessive haemorrhage. ${ }^{1-8}$ The clinician who is faced with a warfarinized patient requiring extractions has to balance the risk of reducing or stopping the anticoagulant therapy with that of excessive bleeding. Traditionally emphasis has been given to stopping bleeding by altering the warfarin dosage. However, cessation or decrease in the anticoagulant therapy exposes the patients, especially those with artificial heart valves, to the risk of thromboembolism. ${ }^{9-14}$ Most patients and health professionals, when given the choice of some oral bruising or oozing versus potential stroke or similar catastrophic event, choose not to risk stopping their anticoagulant. Various protocols have been suggested for dental extraction in anticoagulated patients. ${ }^{15}$ There is no standard therapeutic approach to these patients and it appears that each patient's treatment plan is tailored by their cardiologist, local medical officer, and dentist. In support of the hypothesis that impaired haemostasis is the result of either deficient coagulation (impaired fibrin deposition) or increased fibrinolysis (fibrin resolution), local measures to inhibit fibrinolysis have evolved and enabled dental extractions to now be performed in therapeutically warfarinized patients on an outpatient basis.

\section{Overview of the haemostatic and fibrinolytic systems}

In connection with vascular injury, the integrity of the vascular system is maintained by the haemostatic mechanism. Through this physiologic mechanism, haemorrhage is arrested at the site of injury between four biological systems: the vessel wall, the platelets, and the coagulation and fibrinolytic systems (Fig 1).

\section{The vessel wall}

When a vessel is injured, vasoconstriction occurs as an early event, in order to reduce the blood flow and extravasation of blood components. The vasoconstriction of arteries and arterioles is under neural control, whereas the constriction of smaller vessels (including capillaries) is controlled by humoral 


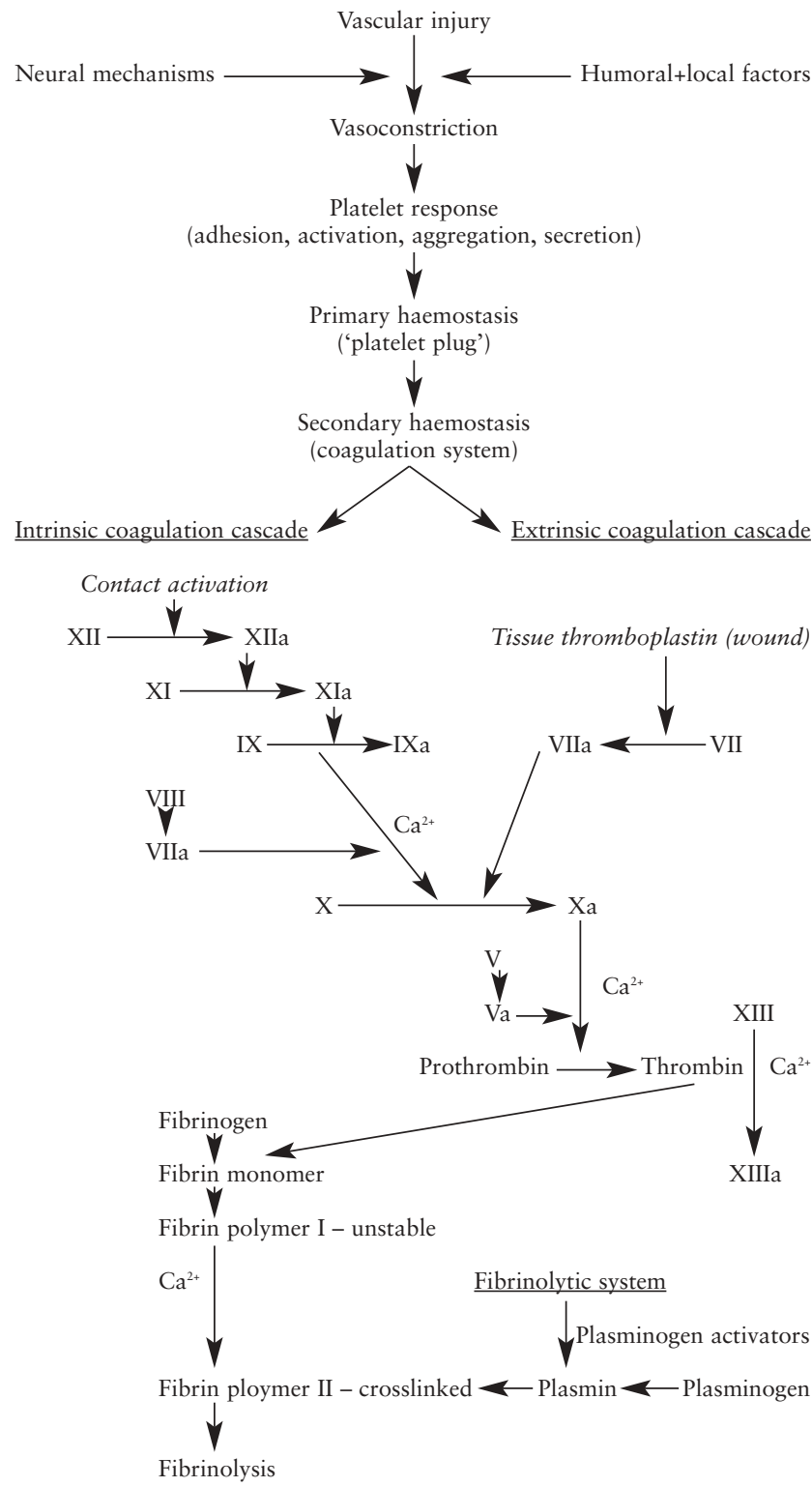

Fig 1. Interaction between the haemostatic and fibrinolytic systems.

and local factors. Compounds such as adenosine diphosphate (ADP), serotonin and Thromboxane A2, released from platelets, potentiate vasoconstriction. ${ }^{16}$

\section{The platelets}

When platelets are exposed to an injured vessel wall, they will adhere to the thrombogenic subendothelial structures and in particular to perivascular collagen. Von Willebrand factor, fibronectin and fibrinogen present in plasma, as well as in a granules in platelets, bind to the platelet membrane, and are important for platelet adhesion. Platelets are initially activated by substances such as ADP, adrenaline, serotonin, thrombin, platelet activating factor, and collagen, which bind to the platelet membrane and change its surface morphology. This is followed by granular secretion and activation. The activated platelets participate in the coagulation process and provide a surface for assembly, activation and binding of coagulation proteins subsequently activated in a sequential manner. ${ }^{17}$ Platelet adhesion is followed by a continuous aggregation mediated by ADP, thromboxanes and prostaglandins. The aggregated platelets form the platelet plug, which is responsible for immediate (primary) haemostasis. This platelet plug appears to serve as a surface for the formation of a clot where the blood coagulation factors are active. The clot and the platelet plug are necessary for effective haemostasis. The bleeding time is used to test primary haemostasis.

\section{The coagulation system}

The coagulation system converts the plasma protein fibrinogen into fibrin by the enzyme thrombin. The process includes several reactions occurring in a cascading-like manner, and can be initiated by two different pathways, the intrinsic pathway (factor XIIdependent) and the extrinsic pathway (thromboplastindependent). While the two systems differ in methods of activating the coagulation system, they share a common pathway for production of fibrin. In the intrinsic system, a circulating surface-sensitive protein, the Hageman factor (factor XII), is activated on contact with a foreign surface. This contact (and subsequent reaction) initiates the coagulation cascade. Factor XII can be activated by contact with collagen, vascular basement membrane, activated platelets, or phospholipids from platelets. The process ultimately results in the polymerization of fibrin, which is then stabilized by factor XIII. The intrinsic pathway is assessed by the activated partial thromboplastin time (APTT). In the extrinsic system tissue thromboplastin elaborated at the site of tissue injury forms complexes with factors V, VII, and X in the presence of calcium ions to convert prothrombin to thrombin. This system also facilitates aggregation of platelets and enhances the activity of the intrinsic system. ${ }^{18}$ The extrinsic system is assessed by the International Normalized Ratio (INR) or prothrombin time (PT).

\section{The fibrinolytic system}

Physiological fibrinolysis has been defined as the degradation of fibrin by the enzyme plasmin. The conversion of the zymogen plasminogen to the active enzyme plasmin is a fundamental phase in the activation process. Plasminogen is a circulating plasma protein produced in the liver that is activated by two different pathways of which the extrinsic fibrinolytic system is dependent on activators bound in the tissues (tissue plasminogen activator-t-PA), and the intrinsic fibrinolytic system on humoral precursors circulating in the blood. Activation of the pathways results in the conversion of plasminogen to plasmin.

The possible pathogenic role of local fibrinolysis in the oral cavity on bleeding after oral surgery in healthy individuals, as well as patients with defects of the coagulation system has been suggested by several authors. ${ }^{19-20}$ Fibrin deposited in the oral cavity can be resolved both by the activation of blood fibrinolysis as 
Table 1. Commonly accepted indications for oral anticoagulant treatment, and aims of treatment

1. Venous thrombosis and pulmonary embolism: Primary prevention

Treatment of established thrombosis

Secondary prevention

2. Myocardial infarction:

Prevention of venous thromboembolism

Prevention of systemic embolism

Prevention of re-infarction

3. Valvular heart disease, prosthetic heart valves, cardiac arrhythmia and cardiomyopathy: Prevention of systemic embolism

4. Systemic embolism: Secondary prevention

5. Transient cerebral ischaemia:

Prevention of recurrent transient ischaemia

Prevention of stroke

6 Reconstructive artery surgery and atherosclerotic peripheral vascular disease:

Prevention of thrombotic occlusion

well as by the plasminogen activators in the oral environment. An increased fibrinolytic activity in the fluid from gingival crevices in patients with periodontal disease, as compared to subjects with healthy gingiva, has previously been reported. ${ }^{21}$ The presence of activators of fibrinolysis associated with oral epithelial cells and in the saliva has also been demonstrated, ${ }^{19,22-27}$ as has the absence of inhibitors of fibrinolysis in the saliva. ${ }^{28-29}$

\section{Warfarin}

Warfarin is a vitamin $\mathrm{K}$ antagonist that impairs the liver synthesis of coagulation factors II, VII, IX and X, and endogenous proteins $\mathrm{C}$ and $\mathrm{S}$ affecting both the intrinsic and extrinsic coagulation pathways, resulting in impaired fibrin formation.

\section{Indications for use}

Oral anticoagulants such as warfarin are considered effective in the prophylaxis and treatment of venous thromboembolism, ${ }^{30-31}$ and for the prevention of systemic emboli from a cardiac source..$^{32}$ The aim of anticoagulant therapy is to reduce the coagulability of blood into an optimal therapeutic range within which the patient is protected against thrombosis at the cost of being exposed to a small risk of spontaneous bleeding. Commonly accepted indications for warfarin treatment and the aims of treatment are summarized in Table 1.

\section{Pharmacokinetics}

Warfarin is rapidly absorbed from the upper gastrointestinal tract, and is highly protein bound but it is the free fraction only that is pharmacologically active. The half-life is independent of the dose but usually falls within the range of 35-45 hours. Warfarin is distributed to approximately 8 to 27 per cent of the body weight, which is similar to that of albumin (to which it is bound). Warfarin is completely metabolized by the liver and subsequently eliminated by the kidneys.
Table 2. Therapeutic levels of anticoagulation and treatment duration

\begin{tabular}{|c|c|c|c|}
\hline Clinical state & INR & $\begin{array}{l}\text { Therapeutic range } \\
\text { using rabbit brain } \\
\text { thromboplastin } \\
\text { (ISI value }=2.3 \text { ) }\end{array}$ & Duration \\
\hline $\begin{array}{l}\text { Prophylaxis - venous } \\
\text { thromboembolism } \\
\text { (high-risk surgery) }\end{array}$ & $2.0-3.0$ & $1.35-1.6 \times \mathrm{PT}^{\circ}$ & Variable \\
\hline $\begin{array}{l}\text { Prophylaxis - venous } \\
\text { thromboembolism } \\
\text { (hip surgery) }\end{array}$ & $2.0-3.0$ & $1.35-1.6 \times \mathrm{PT}$ & Variable \\
\hline $\begin{array}{l}\text { Treatment of deep } \\
\text { venous thrombosis, } \\
\text { or pulmonary } \\
\text { embolism }\end{array}$ & $2.0-3.0$ & $1.35-1.6$ x PT & $\begin{array}{l}\text { Three } \\
\text { months } \\
\text { Six } \\
\text { months }\end{array}$ \\
\hline $\begin{array}{l}\text { To prevent systemic } \\
\text { embolism in patients } \\
\text { with atrial } \\
\text { fibrillation, valvular } \\
\text { heart disease, tissue } \\
\text { heart valves, or } \\
\text { acute myocardial } \\
\text { infarction }\end{array}$ & $2.0-3.0$ & $1.35-1.6 \times \mathrm{PT}$ & Lifelong \\
\hline $\begin{array}{l}\text { Mechanical prosthetic } \\
\text { heart valves, } \\
\text { recurrent systemic } \\
\text { embolism }\end{array}$ & $2.5-3.5$ & $1.5-1.7 \times$ PT & Lifelong \\
\hline
\end{tabular}

\section{Monitoring - Prothrombin time test/INR}

Since the early 1940s the PT method developed by Quick has been the primary means of monitoring the level of anticoagulant control. ${ }^{33}$ The test is performed by adding thromboplastin to citrated patient blood. By the late 1970s there were many commercial thromboplastins available, with differing levels of sensitivity. Subsequently, in 1978, the World Health Organization (WHO) recommended that the PT be standardized. In 1983, the WHO published the recommendations for reporting the level of anticoagulation using an INR. The INR was developed to normalize the PT test based on the sensitivity of different thromboplastins. As a result, an INR is essentially the same regardless of which thromboplastin a particular laboratory uses. An INR of 1 corresponds with a normal haemostatic capacity. Therapeutic levels of anticoagulation are reached with INR values between 2 and 3.5. When the INR is 5 or higher, there is a serious risk of spontaneous bleeding episodes. In 1986, an Ad Hoc committee sponsored by the American College of Chest Physicians (AACP) and the National Heart, Lung and Blood Institute formulated new guidelines for anticoagulation..$^{34}$ The committee reviewed the literature and clinical findings and determined that patients could be treated with lower doses of warfarin than used previously to prevent thrombosis and at the same time minimize complications associated with anticoagulation (Table 2). Some investigators still recommend higher levels of anticoagulation. ${ }^{35}$

\section{Complications of warfarin therapy}

Complications include bleeding, drug interactions, overdose and rare non-haemorrhagic side effects. By far 
Table 3. Drugs commonly used in dentistry that interact with warfarin

\begin{tabular}{lc}
\hline Drug & Effect on INR \\
\hline Carbamazepine (Tegretol) & $\mathrm{Q} \mathrm{Q}$ \\
Metronidazole & $\mathrm{qq}$ \\
Sulphonamides (trimethoprim, sulfamethoxazole) & $\mathrm{qq}$ \\
Erythromycin & $\mathrm{q}$ \\
Miconazole (oral gel) & $\mathrm{q}$ \\
Tetracycline & $\mathrm{q}$ \\
\hline
\end{tabular}

Note: Prolonged use of any oral antibiotic is not recommended due to potential for gut flora suppression and risk of elevated INR due to vitamin $\mathrm{K}$ deficiency.

Aspirin, NSAIDs: increased risk of bleeding due to antiplatelet effect; avoid concurrent use (except patients at high risk for thromboembolism).

Local anaesthetic agents, paracetamol, and codeine do not interact with warfarin.

the most common complication is bleeding, most commonly simple bruising or haematuria, but bleeding can also be gastrointestinal, intracranial, retroperitoneal and in other sites. Spontaneous bleeding is likely to occur when the INR is excessively prolonged. An excessive INR can be returned to the therapeutic range by either withholding warfarin for one to two days, administering low doses of vitamin $\mathrm{K}$ (0.5-5mg slow iv injection), or infusing a concentrated factor replacement or fresh frozen plasma.

Warfarin is subject to many drug interactions, which may increase or decrease its anticoagulant effect. Important drugs commonly encountered in dentistry and their effects on the INR in patients taking warfarin are summarized in Table 3.

\section{Dental extractions and warfarin}

The controversy surrounding patients taking warfarin who require dental extractions centres on the decision whether to continue or withdraw the medication prior to surgery. Four different philosophies can be distinguished.

\section{1) No change in the warfarin therapy}

It is clear that continuity and consistency of a regimen of anticoagulation are beneficial to all patients who require such therapy. Several authors in the past have published reports recommending leaving the anticoagulant dose unaltered for simple oral surgical procedures such as dental extractions., ${ }^{2,736-40}$ According to these authors, the small but potentially hazardous effect of discontinuing anticoagulant therapy is not justified in patients' anticoagulated within the therapeutic range. However, a closer look at the study populations on which these conclusions were based discloses that in the majority of cases with few or no problems post-operatively, PT values (INR not yet in use) were either on the low side of the therapeutic range or were virtually normal. The most recent literature has recommended that dental extractions can be safely performed in patients therapeutically anticoagulated with warfarin, without the need for topical or regional medication to enhance or stabilize clot formation at the surgical site. ${ }^{41-43}$ Further controlled studies using large
Table 4. Local measures to control bleeding in warfarinized patients undergoing dental extractions

- Local anaesthetic

- Controlled, minimally traumatic surgical technique

- Local pressure with gauze packs

- Sutures

- Absorbable packs (e.g., Surgicel®, Gelfoam®)

- Tranexamic acid mouthrinse, or

- Fibrin Sealant - autologous or donor based

patient groups are required before this technique can be safely advocated.

\section{2) No change in the warfarin therapy plus local measures}

A variety of procedures to secure local haemostasis have been suggested in the literature. The large variation in these procedures indicates a lack in consensus of treatment methods, probably because the suggested methods led to an insufficient reduction in the bleeding complications following dental extractions. A sound surgical technique takes priority when extracting teeth in all patients whether they are taking warfarin or not. Steps to encourage local clotting include: constant application of pressure to the involved tissues even when, for example, a tooth is being luxated; +/- placement of an absorbable pack (e.g., Gelfoam ${ }^{\circledR}$, Pharmacia and Upjohn, Michigan, USA, Surgicel®, Ethicon Inc, New Jersey, USA) in each socket to help serve as a matrix for clot formation; +/- placement of sutures under tension; application of heavy biting pressure in immediate post-operative period and clear verbal + written instructions with regard to mouth care and diet in the post-operative period (Table 4).

The complication of tissue haematoma as a result of a local anaesthetic injection has not been discussed in relation to the dental patient receiving warfarin. That this may be an unrecognized potential problem is evident from the fact that several authors have reported ecchymosis, haematomas, or facial swellings as postoperative complications following dental extractions in patients receiving oral anticoagulants. ${ }^{2,5,7}$ However, in the papers reviewed none of them conjectured as to the cause of these complications, and none gave specific information regarding the local anaesthetic methodology of their protocols. Guidelines developed for the dental treatment of the haemophiliac patient are appropriate in making recommendations for treating the anticoagulated patient. Short 27-gauge needles should be used to allow aspiration and minimize tissue damage. ${ }^{44}$ In addition, the duration of the infusion of the local anaesthetic into the tissue should be for a minimum of $1 \mathrm{~m}$ with $2 \mathrm{~m}$ being preferable..$^{45}$ Periodontal ligament injections may be used where appropriate. Besides injections over bone, intraseptal injections are also considered safe. Injections into highly vascularized areas such as the sites for the posterior superior alveolar nerve block, the long buccal nerve and greater palatine area should be avoided. ${ }^{46}$ The inferior alveolar 
nerve block has the greatest potential for a major complication, as it is possible for a dissecting haematoma to develop which could occlude the airway. The Gow-Gates mandibular block technique is preferable to the conventional inferior alveolar injection or the Akinosi injection because when performed correctly, it has the lowest positive aspiration rate and supplemental injections are not necessary to anaesthetize the buccal and lingual gingivae. ${ }^{47}$ In this case a long needle would be necessary to place the anaesthetic in the proper location.

\section{2a) Tranexamic acid}

It seems that one of the most significant pathogenic factors for the development of bleeding after oral surgery is the activation of fibrinolysis in the oral cavity. In 1989 a study by Sindet-Pederson et al. demonstrated that maintenance of oral anticoagulant therapy in conjunction with oral surgery does not result in severe bleeding complications in patients receiving a tranexamic acid mouthwash post-operatively. ${ }^{6}$ Several other studies have confirmed that anticoagulation treatment does not need to be withdrawn before oral surgery provided that local antifibrinolytic therapy is instituted. ${ }^{48-51}$

Tranexamic acid is the active trans-stereoisomer of amino-methyl cyclohexane carboxylic acid and has been shown to have powerful antifibrinolytic properties. First described by Okamoto and Okamoto in $1962,{ }^{52}$ the molecule is a competitive inhibitor of plasminogen activation and a non-competitive inhibitor of plasmin. Tranexamic acid can be administered systemically or topically. In patients on oral anticoagulants, systemic treatment is not recommended, since these patients run a greater risk of developing thromboembolism. Administration of $10 \mathrm{~mL}$ of a 4.8 per cent tranexamic acid mouthwash results in an average concentration of $7 \mu \mathrm{g}$ of tranexamic acid $/ \mathrm{mL}$ saliva after two hours, and the drug remains at detectable levels in the saliva for eight hours. Since the concentration of tranexamic acid in plasma is barely detectable after use of the mouthwash, ${ }^{6,28}$ there is insignificant inhibition of systemic fibrinolysis and side effects following this treatment are not to be expected, provided the patients follow the directions for using the drug (i.e., do not swallow it). Tranexamic acid has also been shown to accelerate normal wound healing. ${ }^{53-54} \mathrm{~A} 4.8$ per cent mouthwash is available in Australia through the pharmacy department of major hospitals. Patients are advised to rinse with $10 \mathrm{~mL}$ for $2 \mathrm{~m}$ four times a day for two to seven days. ${ }^{51}$ Dentists are able to contact the Hospital pharmacy departments by phone and obtain the prepared mouthwash at a cost of approximately $\$ 15$ to the patient.

\section{2b) Fibrin sealant}

Fibrin sealant has been used for enhancement of local haemostasis after dental extractions for over two decades. ${ }^{55-60}$ Fibrin sealing mimics the last phase of blood clotting, i.e., the conversion of fibrinogen to fibrin. ${ }^{60}$ The preparation may be homologous from a pooled donor source or autologous, derived from the patient's own blood. Several homologous fibrin sealant preparations exist but concern over possible virus transmission has excluded their availability in Australia. The autologous system, which can be prepared through major hospitals, has two components. The first component consists of autologous fibrinogen, Factor XIII, and fibronectin dissolved in a sterile calcium chloride solution (which had been stored in the frozen state at $\left.-70^{\circ} \mathrm{C}\right)$. Bovine thrombin, and an antifibrinolytic drug (to impede clot degradation by the fibrinolytic system) make up the second component. The two components are mixed as they are applied to the surgical site with specialized fibrin glue applicator kit (Fibrijet ${ }^{\circledR}$ Micromedics, Minnesota, USA) comprising a twin syringe assembly (Fig 1). Thrombin converts fibrinogen to fibrin so that clotting is initiated and the mixture solidifies. At the same time thrombin activates factor XIII (in the presence of ionized calcium) which then catalyses the cross-linkage of fibrin, thus increasing the strength of the clot. During wound healing the clot material undergoes gradual lysis and is completely absorbed within two weeks. Aside from its adhesive and haemostatic properties, the sealant has been found to enhance wound healing. Studies comparing the effectiveness of fibrin sealant in patients undergoing dental extractions who are therapeutically anticoagulated with warfarin have shown equally successful outcomes with respect to haemostasis. ${ }^{61-62}$ The disadvantages of fibrin sealant include; necessity for blood donation by the patient (approximately $80 \mathrm{~mL}$ two to three days prior to the proposed surgery), lack of ready availability, exclusion of patients allergic to bovine products (bovine thrombin used); and costcurrently approximately $\$ 300$. Current recommendations for its use in therapeutically warfarinized patients include non-availability of tranexamic acid mouthwash, patients likely to be noncompliant with a mouthwash, and more extensive dentoalveolar procedures such as cystic enucleations. ${ }^{63}$

We propose the following chart when presented with a patient requiring dental extractions who is taking warfarin (Fig 2):

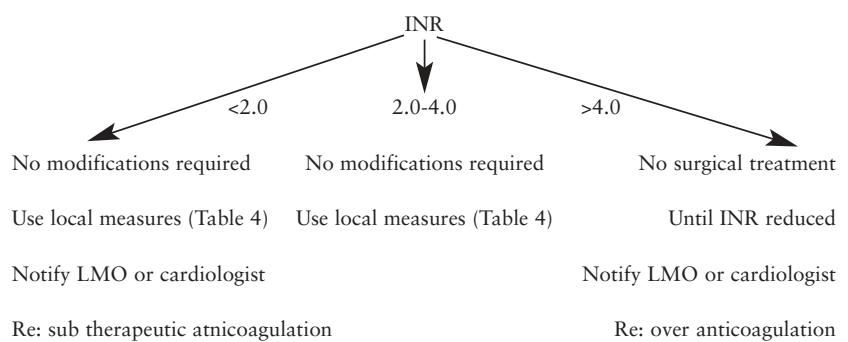

Fig 2. Protocol relating INR to management.

\section{3) Decreasing the level of anticoagulation or temporarily discontinuing the anticoagulant}

In patients in whom the risk of thromboembolism is less of a problem, it has been suggested by some that 
the warfarin should be discontinued a minimum of 48 hours before the surgical visit and re-instituted the day of surgery. ${ }^{64-65}$ This group of patients includes those with previous myocardial infarctions, compensated congestive heart failure, and controlled atrial fibrillation. A reduction or cessation protocol delays necessary dental procedures until the anticoagulation activity can be titrated to an acceptable level. The protocol requires the monitoring of the INR (i.e., multiple blood tests) until it falls within a more acceptable range before beginning treatment. The problem with such a recommendation is that warfarin has a long half-life ( 42 hours) as a result of its slow rate of biotransformation and a high amount of plasma protein binding. It takes more than one day from the withdrawal of the drug for the effect to be evident. In addition even though several texts have recommended a decreasing dosage or cessation of the drug before treatment, the number of days suggested for the altered medication regimen before the initiation of treatment varies from two to six days. ${ }^{66-68}$ This increases the risk of thromboembolism, ${ }^{7,69,70}$ particularly in patients with artificial valves. ${ }^{914}$ In addition, the theory of rebound hypercoagulability after withdrawal of warfarin has been supported by studies that show increased thrombin activity after warfarin withdrawal. ${ }^{71-73}$ Whether or not the rebound phenomenon exists, the patient is exposed to thromboembolic risk for a longer period than the reduction or discontinuation of the warfarin, since it takes a few days for the therapeutic level to be reached. ${ }^{68}$ Even when the two-day withdrawal protocol is followed, the INR should be determined in the immediate pre-treatment period because of the known fluctuations of INR even in the best-maintained patients.

\section{4) Substituting heparin for warfarin}

An alternative approach for patients at high risk for thromboembolism (e.g., prosthetic heart valve replacement) is to discontinue warfarin and introduce heparin to achieve an APTT of 1.5 to 2 times the control. This approach as outlined by Roser and Rosenbloom, ${ }^{74}$ requires hospitalization with close monitoring of the anticoagulant treatment, and is often a very expensive process. The patient's warfarin is ceased 24 hours prior to the admission, and heparin therapy via an intravenous infusion is instituted upon admission. As soon as the INR has decreased to a level appropriate for surgery the patient is scheduled for surgery with the heparin therapy ceased six hours preoperatively. Heparin therapy is recommended 12 to 24 hours post-operatively, depending on the severity of the surgical procedure. Warfarin is re-instituted on the night of the operation. The INR is checked on a daily basis until it is within therapeutic range. When this has been achieved, heparin therapy is discontinued and the patient discharged. This inpatient hospital management protocol usually involves a stay of three to six days at a financial cost of approximately $\$ 3000$ to the public health system as well as a significant social cost to the patient. In effect, the total time the patient remains without anticoagulation ranges from 16-24 hours as opposed to three to four days with the method of discontinuing and re-instituting warfarin discussed previously. While this technique is applicable to all patients on continuous anticoagulant therapy, it is complex and requires interdisciplinary co-operation, hence it has only been recommended for the patient with the greatest risk of thromboembolism and is not the answer for less complicated surgery or for low risk patients.

\section{CONCLUSION}

In the past, the management of patients therapeutically anticoagulated with warfarin requiring dental extractions has posed a dilemma to the attending dental surgeon. The following factors have probably contributed to the favourable evolution of the management of these patients: increased training and experience of dentists; improved dental status of patients, minimizing necessity for multiple extractions and increasing awareness of local fibrinolysis in the oral cavity and the use of local measures. These principles have been taught by the authors over the last decade. They have been tested in formal clinical trials $s^{51,62,63}$ and used on over a thousand patients anticoagulated with warfarin. The result is that all patients can now undergo dental extractions on an ambulatory basis without interruption of their normal warfarin regimen. The cost differential is impressive and obviously represents considerable savings both for the patient and society. However, more importantly the elimination of the need for hospitalization and for multiple venipunctures and infusions provides great comfort and psychological benefit for the patient.

\section{REFERENCES}

1. Ziffer AM, Scopp IW, Beck J, Baum J, Berger AR. Profound bleeding after dental extractions during dicumarol therapy. $\mathrm{N}$ Engl J Med 1957;256:351-353.

2. Waldrep AC, McKelvey LE. Oral surgery for patients on anticoagulant therapy. J Oral Surg 1968;26:374-380.

3. Johnson RL. Blood loss in oral surgery. J Dent Res 1956:175184.

4. Greenberg MS, Miller MF, Lynch MA. Partial thromboplastin time as a predictor of blood loss in oral surgery patients receiving coumarin anticoagulants. J Am Dent Assoc 1972;84:583-587.

5. Scoop JW, Fredrics H. Dental extractions in patients undergoing anticoagulant therapy. Oral Surg Oral Med Oral Pathol 1958;11:470-474.

6. Sindet-Pedersen S, Ramstrom G, Bernvil S, Blomback M. Haemostatic effect of tranexamic acid mouthwash in anticoagulant-treated patients undergoing oral surgery. N Engl J Med 1989;320:840-843.

7. Behrmann SJ, Wright IS. Dental surgery during continuous anticoagulant therapy. J Am Dent Assoc 1961;62:172-180.

8. Declerk D, Vinckier F, Vermylen J. Influence of anticoagulation on blood loss following dental extractions. J Dent Res 1992;71:387-390.

9. Akbarian M, Austen WG, Yurchak PM, Scannell JG. Thromboembolic complications of prosthetic cardiac valves. Circulation 1968;37:826-831. 
10. Lytle BW, Cosgrove DM, Goormastie M, Loop FD. Aortic valve replacement and coronary bypass grafting for patients with aortic stenosis and coronary artery disease: early and late results. Eur Heart J 1988;Suppl E:143-147.

11. Marshall V. Rebound phenomena after anticoagulant therapy in cerebrovascular disease. Circulation 1963;28:329.

12. Gallus AS. Indications for anticoagulation. Drugs 1983;26:543549.

13. Michaels L. Incidence of thromboembolism after stopping anticoagulant therapy. Relationship to haemorrhage at the time of termination. JAMA 1971;215:595-599.

14. Duvoison GE, Brandenburg RO, McGoon DC. Factors affecting thromboembolism associated with prosthetic heart valves. Circulation 1967;35(Supp 1):70-76.

15. Wahl MJ. Dental Surgery in anticoagulated patients. Arch Intern Med 1998;158:1610-1616.

16. Gonias SL, Pizzo SV. The biochemistry of haemostasis. Clin Lab Haematol 1986;8:281-306.

17. Walsh PN. Platelet-mediated coagulant protein interactions in haemostasis. Semin Hematol 1985;22:178-186.

18. Miale JB. Laboratory Medicine Haematology. 6th edn. St Louis: Mosby, 1982:772-859.

19. Bjorlen G, Nilsson IM. Fibrinolytic activity in alveoli after tooth extraction. Odontol Rev 1968;19:197-204.

20. Wedgewood D. The fibrinolytic system with special reference to its relevance to oral surgery. Br J Oral Surg 1970;8:82-92.

21. Hidaka N, Maeda K, Kawakoni C, Aono M, Okada H. Fibrinolytic activity of periodontal disease. J Periodontol 1981;52:181-186.

22. Albrechtsen OK, Thaysen JH. Fibrinolytic activity in human saliva. Acta Physiol Scand 1955;35:138-145.

23. Birn H, Fejerskov O. Fibrinolytic activity of human oral epithelial cells. A preliminary report. Scand J Dent Res 1971;79:381-386.

24. Moody GH. Plasminogen in human saliva. Int J Oral Surg 1982;11:110-114.

25. Moody GH. The source of plasminogen activator in human saliva. Arch Oral Biol 1982;27:33-37.

26. Sindet-Pedersen S, Gram J, Jespersen J. The possible role of oral epithelial cells in tissue-type plasminogen activator related fibrinolysis in human saliva. J Dent Res 1990;69:1283-1286.

27. Rijken DC, Wijngards G, Welbergen J. Immunological characterization of plasminogen activator activities in human tissues and body fluids. J Lab Clin Med 1981;97:477-486.

28. Sindet-Pedersen S, Gram J, Jespersen J. Characterization of plasminogen activators in unstimulated and stimulated human whole saliva. J Dent Res 1987;66:1199-1203.

29. Gersel-Pedersen N. Fibrinolytic activity of blood and saliva before and after oral surgery. Int J Oral Surg 1981;10 (Suppl 1):114-121.

30. Clagett GP, Salzmann EW. Prevention of venous thromboembolism. Prog Cardiovasc Dis 1975;17:345-366.

31. Hull RD, Raskob G, Hirsh J. Prophylaxis of venous thromboembolism. An overview. Chest 1986;89:(5 Suppl)374S$383 \mathrm{~S}$

32. Mitchell JRA. Anticoagulant in coronary heart disease: Retospect and prospect. Lancet 1981;198:257-262.

33. Quick AJ. The prothrombin time in haemophilia and in obstructive jaundice. J Biol Chem 1935;109:73-74.

34. Hirsh J, Levine M. Confusion over the therapeutic range for monitoring oral anticoagulant therapy in North America. Thromb Haemost 1988;59:129-132.

35. Hirsh J, Dalen JE, Deykin D, Poller L. Oral anticoagulants. Mechanism of action, clinical effectiveness and optimal therapeutic range. Chest $1992 ; 102$ (4 suppl):312S-326S.

36. Askey JM, Cherry CB. Dental extraction during dicumarol therapy. Calif Med 1956;84:16-17.

37. Shira RB, Hall RJ, Guernsey LH. Minor oral surgery during prolonged anticoagulant therapy. J Oral Surg 1962;20:93-99.
38. Frank BW, Dickhaus DW, Claus EC. Dental extractions in the presence of continual anticoagulant therapy. Ann Intern Med 1963;59:911-913.

39. Kwapsis B. Anticoagulant therapy and dental practice. J Am Dent Assoc 1963; 66:172-175.

40. Bailey BM, Fordyce AM. Complications of dental extractions in patients receiving warfarin anticoagulant therapy. A controlled clinical trial. Br Dent J 1983;155:308-310.

41. Campbell JH, Alvarado F, Murray RA. Anticoagulation and minor oral surgery: should the anticoagulation regimen be altered? J Oral Maxillofac Surg 2000;58:131-135.

42. Devani P, Lavery KM, Howell CJT. Dental extractions in patients on warfarin: is alteration of anticoagulant regime necessary? $\mathrm{Br} \mathrm{J}$ Oral Maxillofac Surg 1998;36:107-111.

43. Blinder D, Manor Y, Martinowitz U, Taicher S. Dental extractions in patients maintained on continued oral anticoagulant: comparison of local haemostatic modalities. Oral Surg Oral Med Oral Pathol Oral Radiol Endod 1999;88:137140.

44. Malamed SF. Handbook of local anaesthesia. 2nd edn. St Louis: Mosby, 1986:68-82.

45. Duperon DF, Dobbs TM. Dental Care for patients with congenital haemorrhagic disorders. J Can Dent Assoc 1976;42:269-273.

46. Nazif MM. Pain Control in Patients with Haemophilia. In: Powell D, ed. Recent advances in dental care for the haemophiliac. Los Angeles Haemophilia Foundation of Southern California, 1979;58-59.

47. Heine RD. Alternative methods in inferior alveolar anaesthesia. Compend Contin Educ Dent 1985;6:441-448.

48. Borea G, Montebugnoli L, Capuzzi P, Magelli C. Tranexamic acid as a mouthwash in anticoagulant-treated patients undergoing oral surgery. An alternative method to discontinuing anticoagulant therapy. Oral Surg Oral Med Oral Pathol 1993;75:29-31.

49. Ramstrom G, Sindet-Pedersen S, Hall G, Blomback M, Alander U. Prevention of postsurgical bleeding in oral surgery using tranexamic acid without dose modification of oral anticoagulants. J Oral Maxillofac Surg 1993;51:1211-1216.

50. Souto JC, Oliver A, Zuazu-Jausoro I, Vives A, Fontcuberta J. Oral surgery in anticoagulated patients without reducing the dose of oral anticoagulant: a prospective randomized study. J Oral Maxillofac Surg 1996;54:27-32.

51. Carter GD, Goss AN. Tranexamic acid mouthwash - A prospective randomized study of a 2-day regimen vs. 5-day regimen to prevent postoperative bleeding in anticoagulated patients requiring dental extractions. Int J Oral Maxillofac Surg (in press).

52. Okamoto S, Okamoto U. Amino-methyl-cyclohexane-carboxylic acid: AMCHA. A new potent inhibitor of the fibrinolysis. Keio J Med 1962;11:105-115.

53. Bjoerlin G, Nilsson IM. The effect of antifibrinolytic agents on wound healing. Int J Oral Maxillofac Surg 1988;17:273-276.

54. Vinkier F, Vermylen J. Wound healing following dental extractions in rabbits: Effects of tranexamic acid, warfarin anticoagulation, and socket packing. J Dent Res 1984;63:646-649.

55. Martinowitz U, Mazar AL, Taicher S, et al. Dental extraction for patients on oral anticoagulant therapy. Oral Surg Oral Med Oral Pathol 1990;70:274-277.

56. Rakocz M, Mazar A, Varon D, Spierer S, Blinder D, Martinowitz U. Dental extractions in patients with bleeding disorders: The use of fibrin glue. Oral Surg Oral Med Oral Pathol 1993;75:280282.

57. Wepner F, Fries R, Platz H. The use of the fibrin adhesion system for local haemostasis in oral surgery. J Oral Maxillofac Surg 1982:40:555-558.

58. Zusman S, Lustig J, Baston I. Postextraction haemostasis in patients on anticoagulant therapy: the use of a fibrin sealant. Quintessence Int 1992;23:713-716. 
59. Davis B, Sandor G. Use of fibrin glue in maxillofacial surgery. J Otolaryngol 1998:27:107-112.

60. Matras H. Fibrin Seal: The state of the art. J Oral Maxillofac Surg 1985:43:605-611.

61. Schulman S, Rhedin AS, Lindmarker P, et al. A comparison of six weeks with six months of oral anticoagulant therapy after a first episode of venous thromboembolism. Duration of Anticoagulation Trial Study Group. N Eng J Med 1995;332:1661-1665.

62. Carter GD, Goss AN, Lloyd J, Tocchetti R. The comparative effectiveness of a tranexamic acid mouthwash and autologous fibrin glue in patients taking warfarin who require dental extractions - A randomized prospective clinical study. J Oral Maxillofac Surg (in press).

63. Carter G, Goss AN, Lloyd J, Tocchetti. Local haemostasis with autologous fibrin glue following surgical enucleation of a large cystic lesion in a therapeutically anticoagulated patient: a case report. Br J Oral Maxillofac Surg (in press).

64. Mulligan R. Response to anticoagulant drug withdrawal. J Am Dent Assoc 1987;115:435-438.

65. Kearon C, Hirsh J. Management of anticoagulation before and after elective surgery. N Eng J Med 1997;336:1506-1511.

66. Davis FB, Sczupak CA. Outpatient oral anticoagulation: guidelines for long-term management. Post Grad Med 1979;66:100-109.

67. Kovacs B, Toth K, Kerenji G. Post-extraction haemostasis during coumarin anticoagulant therapy with a locally applied coagulation-active substance. Int J Oral Surg 1976;5:3-7.
68. Sonis L, Musselman RJ. Oral bleeding in classic hemophilia. Oral Surg Oral Med Oral Pathol 1982;53:363-366.

69. Cosgriff SW. Chronic anticoagulant therapy in recurrent embolism of cardiac origin. Ann Int Med 1953;38:278.

70. Tulloch J, Wright IS. Long term anticoagulant therapy: further experiences. Circulation 1954;8:523.

71. Roller L, Thomson JM. Evidence for rebound hypercoagulability. Lancet 1964;2:62.

72. Marshall J. Rebound phenomena after anticoagulant therapy in cerebrovascular disease. Circulation 1963;28:329.

73. Harenberg J, Haas R, Zimmerman R. Plasma hypercoagulability after termination of oral anticoagulants. Thromb Res 1983;29:627-633.

74. Roser SM, Rosenbloom B. Continued anticoagulation in oral surgery procedures. Oral Surg Oral Med Oral Pathol 1975;40:448-457.

Address for correspondencelreprints: Professor AN Goss

Oral and Maxillofacial Surgery Unit

The University of Adelaide

Adelaide, South Australia 5005

Email: oral.surgery@adelaide.edu.au 